\title{
Memoria y olvido de las mujeres republicanas
}

\author{
Pilar Domínguez*
}

Uno de los períodos clave para el cambio social en la España del siglo XX fueron los años de la II República y la Guerra Civil.

La guerra civil ha sido un motivo privilegiado desde el punto de vista historiográfico por la abundancia de fuentes escritas, sonoras y gráficas, generadas por un conflicto de considerables repercusiones internacionales. Poco a poco se ha ido recuperando a los individuos "protagonistas» de esta historia, que en este caso son las mujeres. Se trata de darles voz, de permitirles contar "su" historia, porque como decía una activista republicana:

Nos parece que en este momento es interesante el testimonio de todos, porque los testimonios son diferentes, ni mejores, ni peores, porque... los ambientes han dejado un recuerdo que a veces se modifica, porque a veces no es tanto el recuerdo cuanto las cosas que hemos oído después. (Entrevista a María Teresa, marzo de 1992)

De ese complejo entramado de voces, recuerdos y reflexiones que se elaboran desde el presente hacia el pasado y que constituyen los testimonios orales, nos interesa resaltar algunas narraciones orales femeninas de la guerra. Tratamos de ver lo específico de estas experiencias femeninas, percibidas y reconocidas como diferentes de las experiencias masculinas de la contienda, pero también muy plurales.

* Universidade de Las Palmas de Gran Canaria, Espanha. 
Para ello hemos recuperado los relatos de vida de dos mujeres, María Gallegos y Aurora Arnaiz, que en su juventud vivieron la Guerra Civil, con experiencias muy diversas aunque siempre traumáticas. Con la derrota republicana, a ambas les tocó vivir la salida forzosa de España hasta que llegaron a la ciudad de México, donde han residido desde entonces. Allí las entrevisté a mediados de los años ochenta.

Sus relatos orales se refieren tanto a sus vivencias del período republicano como al exilio; aquí sólo nos referimos a la primera parte y en especial a sus relatos de la Guerra Civil. Estas vivencias de la guerra marcaron profundamente su trayectoria vital, según la opinión de ellas mismas y ocupan un lugar privilegiado en su proceso de rememoración.

Nuestras dos entrevistadas, María G. y Aurora A. pertenecen a la misma generación en sentido biológico, pues nacieron entre 1910 y 1914 , pero no son de la misma generación social, en el sentido que le da Paloma Aguilar (1996, 2008), ya que no vivieron en un tiempo y en un espacio histórico comunes que son los que "predisponen hacia una forma de pensamiento, experiencia y un tipo específico de acción históricamente relevante" (Manheim, 1952, apud Aguilar, 2008, p. 32). Las enormes diferencias entre la vida en la industrializada Bilbao de las primeras décadas del siglo XX y la ciudad andaluza de Málaga separan sus ambientes sociales de procedencia abriendo una brecha en su formación.

Así la educación que recibieron en su patria "chica" fue también muy distinta; mientras que María vivía en Málaga en el seno de una familia de escasos recursos, conservadora y muy religiosa, que no consideraba necesario que las niñas estudiaran, Aurora se había criado en el ambiente obrero socialista y laico del País Vasco (Bilbao). Sus memorias autobiográficas representan vivencias muy distintas del período republicano y la guerra civil e incluyen tanto sus recuerdos de los hechos vividos, como sus valoraciones sobre el pasado.

El hecho de relatar la propia vida a otra persona es un medio de inventar el propio yo, de darle una identidad narrativa, según han observado diversos autores (Passerini, 1985; Ricoeur, 2000). La construcción identitaria del narrador también varía en función de la capacidad lingüística del individuo, de manera que el lenguaje y la memoria están interconectados (Llona, 2006). Indagando sobre esta peculiar identidad observamos que cada una de las entrevistadas adopta una forma de expresión narrativa diversa, muy relacionada con su formación educativa y con su 
trayectoria vital. En la construcción de esas identidades vamos a fijar la atención en este artículo.

María Gallegos a lo largo de su entrevista usa un lenguaje sencillo y directo y se autorrepresenta como una mujer tradicional, una "ama de casa apolítica". Ella se consideraba una víctima de las circunstancias de la guerra, pues afirmaba que "pagó (con la cárcel) las culpas de su marido", un activo militante republicano del Partido Radical Socialista. Su trayectoria vital está marcada por el trauma de este encarcelamiento en plena guerra. Esta terrible experiencia truncó su apacible vida de madre de familia con dos hijos, centrada en el hogar y alejada del escenario político.

En contraposición, el relato de Aurora ejemplifica el nuevo modelo de mujer republicana, instruida y la vez implicada en la lucha política. En su entrevista se autorrepresenta como socialista casi desde su nacimiento, debido a la fuerte influencia que ejerció en ella su padre, "el viejo Arnaiz". Esta identidad política, que aparece ya desde el comienzo de su historia de vida, da sentido y coherencia a su trayectoria vital, a las responsabilidades políticas que ella fue asumiendo en la República y la Guerra Civil y finalmente a su decisión de salir de España rumbo al exilio.

En el contexto de la guerra civil, veremos algunos aspectos de estas dos narraciones orales. Cada una de ellas va precedida por una frase de la propia entrevistada que "establece su tono vital” (Plá, 2003) y nos da el sentido que para ella tiene su narración. ${ }^{1}$

\section{María Gallegos: "Estuve metida en la cárcel como una criminala, sin haber hecho ná... i Y yo qué culpa tenía!"}

Como vemos por esta frase de María que da título al comentario sobre su entrevista, ella se consideraba una víctima de la guerra, sin capacidad de control sobre los acontecimientos. La infancia y juventud de María, nacida en 1910, transcurrieron apaciblemente en Málaga, donde su padre tenía un pequeño negocio de zapatería que no daba suficiente para alimentar a su numerosa familia de diez hijos. Ella, como sus hermanas, tuvo que

1 La autora sigue aquí la metodología de Sebe Bom Meihy en la "transcreación de la entrevista" y toma una frase significativa del entrevistado/a como título de cada uno de los relatos del exilio que componen su libro. 
trabajar desde niña cosiendo a máquina las plantillas de los zapatitos de bebé, mientras que recibía una escolarización deficiente y discriminatoria en un colegio de monjas. Esto le llevaba en el momento de la entrevista a la siguiente reflexión crítica:

Lo burra que yo he sido, no quiero que mi hija sea... Los hombres si... mi marido estudió, mis hermanos estudiaron; el hombre es el que tenía que estudiá, la mujer ná más que pa parir, pá criar niños ... la sirvienta ¿no es cierto?; pa llevar la casa adelante, volverle el cuello a la camisa y cosé y hacé de comer. Para eso la enseñaban a una.

Ella seguía entonces los pasos del modelo tradicional de feminidad y muy pronto - a los once años- se hizo novia de Paco, el que luego fue su marido, tras ocho años de relaciones. El relato del noviazgo y el nacimiento de sus hijos, de todo lo referente a la vida privada, forma una parte fundamental de su historia de vida, como suele ocurrir en los relatos de vida femeninos. Por el contrario, los acontecimientos políticos del período republicano son recordados vagamente por nuestra entrevistada, a pesar de que su marido formaba parte del Comité Local que el 14 de abril de 1931 había proclamado la República en Málaga. Tampoco recordaba haber votado durante la República, hasta que su marido le asegura que en 1936 ella había votado a su partido. ${ }^{2}$ A lo largo de su relato llama la atención las constantes confusiones entre unos hechos históricos y otros -el 14 de abril es confundido con el 18 de julio del 36, fecha del inicio del golpe militar franquista contra la República. Estos olvidos indican que esas fechas "históricas" no eran significativas en su percepción del tiempo, más guiado por sus experiencias familiares. Sin embargo estos "fallos" de la memoria dieron lugar en la entrevista a las frecuentes intervenciones de su marido en el relato, interrumpiendo su discurso de forma paternalista, para corregirla y precisar datos y fechas.

La Guerra Civil supuso una experiencia brutal para la mayoría de la población española, aunque las mujeres la sufrieron de una forma parti-

2 El diálogo dentro de la entrevista es el siguiente:

[María:] - Yo nunca voté. Yo no era de nada. ¿Yo voté?

[Marido: ] - Sí. ¿Cómo no?

[María: ] - Yo lo que él me daba [para votar]

[Marido:] - Je, je, pues sí. 
cular. Los testimonios orales, como los que aporta María, nos ofrecen vívidos recuerdos de esta tragedia. Muchas familias sufrieron muertes y separaciones por la situación de los frentes; a menudo las mujeres y los niños tuvieron que ser evacuados de sus lugares de origen, pasando a formar parte de la gran masa de refugiados en la ciudad.

A diferencia de otras exiliadas, María no había participado en actividades políticas durante la República y la guerra, pero bastó que su marido fuera un conocido militante republicano para que tuviera que salir de Málaga, el año 1937, debido al avance de los italianos y los franquistas hacia la ciudad. Al huir su marido al bando republicano, ella se quedó sola en la ciudad por lo que pronto fue encarcelada, como represalia. La represión específica de género contra las mujeres de los republicanos, rapándoles el cabello, llevándolas a la cárcel e incluso a la muerte, fue una práctica habitual entre los vencedores del bando franquista. María todavía lo narraba con angustia casi cincuenta años después:

Yo en la guerra no hice ná; yo no tenía idea ninguna...

Entonces decía mi padre a un señor: don Juan Márquez:

- Oiga don Juan, mi hija que no ha hecho ná la pobre, que es inocente ¿por qué está presa?

Dice: - No es por ella, don Manué, está por el marido.

- Pero si mi yerno es una bella persona.

- Pero él hacía propaganda de izquierda pa la guerra.

¡Y yo aquí pagando su culpa de él!

En esta última frase ella recalca su inocencia frente a la culpabilidad del marido doblemente adjetivada (su y de é).

Así pues, la mayoría del relato oral de María se centra en su detención y encarcelamiento, una experiencia traumática para una joven de veinticinco años con una hija casi recién nacida. Su relato rememora con viveza el diálogo que mantuvo en el momento de su detención con un miembro de la Guardia Civil, un hecho dramático que todavía alteraba su estado de ánimo en el momento de la entrevista y que ella relataba, de esta manera, en un presente histórico:

- Oiga, que tiene usted que venir con nosotros al cuartel.

Digo: - Ay, que le voy a dar a la niña el pecho. 
- No, no importa no se lo dé, es para una pequeña declaración y ahora vuelve usted.

Ay, le tengo horror, eh, [a la Guardia Civil]...Cuando me acuerdo de todo esto me hincho a llorar... me pongo hasta nerviosa.

A partir de la narración de su detención en Málaga, en 1937, tras la llegada de las tropas fascistas italianas a la ciudad, el tono de su relato cambia haciéndose más reflexivo y crítico con las instituciones del estado franquista, como la Guardia Civil. Recuerda muy bien los interrogatorios y cómo le pegaron en la cárcel para obtener información sobre su marido, así como las consecuencias físicas de su detención. Rememoraba así uno de los diálogos que mantuvo con los guardias:

[Guardia Civil:] - Mire, ¿no lo ve que tiene cara de "roja” ¿Dónde está su marido?

- Yo no lo sé. No lo tengo guardao...

La Guardia Civil es mala, oiga... Se me fue el período y estuve cinco años sin período. ${ }^{3}$

El maltrato que recibió afianzó su consideración negativa de la actividad política, repite varias veces:

La política qué horror, qué cosa tan horrible... el único que estaba metido en el jaleo era mi marido, y yo que culpa tenía...

Asumiendo su papel de ama de casa, reconoce que "no entendía de eso", por estar dedicada a "las cosas de la casa". Esto no le impide declararse republicana: "A mi me gustaba la República (...) yo oía que había más libertad y todo eso".

Su narración prosigue con los años de la dura posguerra española, que ella vivió durante siete años. Su actitud ante el nuevo régimen se hizo cada vez más hostil aunque ella no lo exprese desde una posición ideológica determinada. Rememora, sin embargo, los fusilamientos arbitrarios que pudo ver en la cárcel de mujeres y en especial la actitud revanchista de la Iglesia católica ejemplificada en las ofensas del cura, que quería obli-

3 Los "rojos" eran los republicanos, para la terminología franquista. Con el término "periodo" se refiere a la menstruación. 
garle a decir que "odiaba a todos los rojos que huyeron", sabiendo que su marido era republicano y se había visto obligado a huir de Málaga.

En el nuevo estado nacional-católico la doctrina de la Iglesia sobre la naturaleza y el comportamiento de las mujeres fue tomada como base para toda la sociedad que debía ser recristianizada tras las experiencias del laicismo y los postulados igualitaristas de la II República. Los sacerdotes ejercían su autoridad sobre la población, en especial sobre las mujeres, inculcando a la población femenina sus normas morales e incluso dictando su forma de vestir, el llamado "vestir cristiano". En palabras de María se trataba de "ir vestida de oscuro como si fuera una vieja".

En esa situación, cansada del ambiente opresivo que se respiraba en Málaga de la posguerra, María hizo lo posible para reunirse con su marido, exiliado en México y, finalmente, consiguió salir de España con su hijo el año 1944: habían pasado siete años desde que se habían separado por la guerra.

\section{Aurora Arnaíz: "Mi padre siempre fue socialista, a noso- tros nos enseñó a leer y a escribir en los escritos de Pablo Iglesias"}

Esta frase de Aurora destaca la importancia que concede a la figura del padre - obrero y sindicalista - como su principal educador y responsable de su interés por la política, actividad en la que centraba gran parte de su relato oral. Así resume una forma de autorrepresentación, como "socialista desde la cuna", muy distinta a la de María. La trascendencia de esta formación ideológica temprana llegará hasta el exilio. Dice al respecto:

Yo nunca fui pueblerina...mi padre nos enseñó siempre una visión universal...yo creo que eso me ayudó en el exilio a compenetrarme con el nuevo país"

Su narración continúa con la temprana formación de Aurora en las ideas del socialismo, dentro de los "Círculos infantiles socialistas" de Bilbao. Ya a los dieciocho años formó parte de la Junta organizadora de la FUE (Federación Universitaria Escolar) en el País Vasco y luego militó en las Juventudes Socialistas de Madrid. Por otra parte relataba como ella 
recibió una educación poco usual para las jóvenes de su tiempo; primero estudió el bachillerato en un colegio privado laico y luego fue a la universidad de Madrid a estudiar Derecho, su gran vocación que pudo continuar más tarde en México, hasta llegar a ser profesora de la UNAM.

En contraste con el testimonio anterior, su relato de los años de la República se refiere sobre todo a su actividad pública, sin que haga apenas referencias a su vida privada:

Yo me dedicaba a mis estudios y a mi trabajo político...Carmen Parga $^{4}$ y yo fuimos las primeras en hacer las pintadas en la facultad de Derecho. [...]

Yo creo que soy la única mujer Comisario de Brigada. Sí, de la Brigada Largo Caballero... A las Comisarías Políticas que teníamos puestos en la retaguardia, las juventudes, los partidos, nos empleaban como cuadros de dirección. Se trata de mujeres de fuerte personalidad que se imponen, pero que se imponen por su capacidad; pero dar oportunidad (a las mujeres) y elevar, y educar y formar en altos puestos de dirección, no; eran funciones subalternas.

Como vemos, aquí Aurora se identifica como una mujer dedicada a la actividad política, "de fuerte personalidad", algo necesario para que las mujeres pudieran superar las discriminaciones de género que las colocaban en posiciones subordinadas. De hecho ella, con sólo 22 años, ya formaba parte de la Ejecutiva Nacional de las Juventudes Socialistas. Prosigue su relato centrado en la actividad política:

Durante toda la guerra estuve en Madrid... en la Junta Nacional de las Juventudes Socialistas y me tocó a mí salir el 7 de noviembre, cuando el cerco, para Valencia con los enfermos, con mujeres y con niños... con una comitiva que llevábamos además el archivo de las Juventudes Socialistas y supongo que dinero. Antes de llegar a Valencia estaban allí todos los jefes militares de la guerra y una mujer muy interesante, Federica Montseny. A los pocos días me regresé a Madrid... yo creo que me sacaron del Comité de las JSU

4 Carmen Parga era otra republicana española exiliada en México. 
por indisciplinada, porque me largué de Valencia y me presenté en

Madrid; mi marido era el director general de Seguridad. ${ }^{5}$

Aurora, pasó casi toda la guerra en Madrid y allí fue dirigente del nuevo grupo de la "Unión de Muchachas". La organización había sido formada en 1937 por jóvenes de las Juventudes Socialistas Unificadas de Madrid - como la misma Aurora - y se creó con el objetivo de reclutar chicas de 14 a 25 años para trabajar en todo tipo de tareas de la retaguardia, en los talleres y en las fábricas que tejían uniformes para el frente o preparaban el armamento.

Su actividad como dirigente política no era nueva para Aurora sino que enlazaba con la que había desarrollado en el período republicano en el seno de las Juventudes Socialistas y la Casa del Pueblo de Madrid. En este sentido dice:

Yo tenía una experiencia enorme en la tribuna (como oradora)... Teníamos reuniones con las mujeres en los sindicatos, y había que darles la educación política. A mi me gustaba salir a hablar y a convencer.

En relación con este tema son muy reveladoras de su mentalidad política las reflexiones que hace en torno al feminismo. La educación política a la que se refiere no incluía entonces hablar a las mujeres de las desigualdades de género en el trabajo o en la familia sino ganarlas para la causa antifascista y republicana. En consonancia con ello Aurora afirmaba: "Yo feminista jamás fui... Yo siempre tuve la idea de que la mujer debe integrarse en la sociedad".

Para los socialistas de entonces, e incluso para las militantes de organizaciones de mujeres como la Agrupación de Mujeres Antifascistas, el feminismo era un movimiento pequeño-burgués que sólo se centraba en los problemas particulares de las mujeres.

Destaca en el relato de Aurora las escasas referencias a su vida privada durante el período republicano y la guerra civil, en contra de lo que suele suceder en las historias de vida femeninas. Sólo al hablar de los ava-

5 El 7 de noviembre de 1936 el gobierno republicano y los cuadros de los principales partidos abandonaron la capital que estaba cercada por los franquistas. Los republicanos resistieron al cerco pero el gobierno no regresó ya a Madrid. Al final de la cita hay una discrepancia sobre el cargo de su marido, luego en sus memorias escritas figura que él fue Gobernador de Guadalajara. 
tares de la guerra nos contó que su marido tuvo que quedarse en Madrid y ella regresó a la capital para reunirse con él, desobedeciendo las órdenes de la Ejecutiva. A continuación su relato pasaba a explicarnos cómo al ser inminente la derrota de la República, tras el golpe militar de Casado en Madrid, ella consiguió salir de España rumbo a Francia en marzo de 1939.

La brevedad de la narración oral de estos hechos durante la guerra escondía terribles sucesos como la muerte de su bebé y el fusilamiento de su marido, ocurridos ambos al final de la guerra civil, acontecimientos que ella prefirió omitir en la entrevista, seguramente debido al dolor que le causaba su rememoración. Su tragedia personal era un tema sobre el que en ese momento no sentía necesidad de hablar.

Sin embargo, el relato de su drama personal aparece detallado en sus memorias, redactadas años más tarde con el nombre de Retrato hablado de Luisa Julián (Arnaiz, 1996). ${ }^{6}$ Allí contaba la enfermedad y la muerte de su hijito, sin asistencia médica, en los últimos días de la guerra en Madrid. Más adelante, en el apéndice del libro - lo titula "Post Scriptum" - narra la detención y la muerte de José Cazorla, su marido; allí aparecen informaciones sobre este hecho recogidas de otros testimonios orales de supervivientes de la represión franquista, mezcladas con recuerdos propios, como el de su matrimonio civil en 1937, que tampoco había relatado en la entrevista. Era un recuerdo como muchos otros, triste, pero como ella escribía:

"Dispuesto a irrumpir en incontenible desborde de emoción una vez que logró abrir la llave del claustro de sus enterrados recuerdos". (Idem, p. 282)

\section{Conclusiones}

Los relatos orales de estas dos mujeres muestran la variedad de las memorias individuales surgidas del trauma del conflicto bélico y cómo pueden ser muy diversas las estrategias de la memoria y la rememoración (Vilanova, 2003) Éstas varían en función de las experiencias vividas, pero también de la formación personal.

6 Luisa Julián fue su "nombre de guerra” como militante de las JSU. 
Los relatos que sintetizan y valoran más las experiencias suelen corresponder a individuos más cultos y más comprometidos políticamente, como ocurre el caso de Aurora; durante la entrevista deja de lado su tragedia personal, que prefiere olvidar en ese momento, y a cambio nos da una visión más valorativa de los acontecimientos, y de su trayectoria centrada en la política. Por otra parte, María rememora los acontecimientos desde su papel de víctima de una guerra, en la que ella -en un principiono se sentía involucrada.

Los relatos orales muestran junto a la memoria, el olvido, que trae a colación el problema de la falta de fiabilidad de la memoria. Este olvido tiene también distintos matices en cada entrevista; desde el olvido involuntario de fechas históricas señaladas en una de ellas, al olvido reversible "de reserva" de sus dramas personales en la otra (Ricoeur, 2003).

Las actitudes frente al conflicto bélico que aparecen en los dos testimonios fueron muy diversas, como reflejo de modelos femeninos también distintos. Para una de ellas, que en la entrevista se definía socialista casi desde la infancia, la guerra supuso el aumento de su compromiso político y de la lucha por "una sociedad más justa". Para la otra, que se consideraba apolítica y se había mantenido siempre en el papel de ama de casa, al margen de la actividad pública, la guerra no fue un gran cambio hasta el triunfo del franquismo. Entonces pasó a ser definida como "mujer de un rojo" y maltratada por los vencedores, lo cual despertó en ella una clara actitud antifranquista.

Sin embargo, el exilio unirá a estas mujeres de trayectorias y memorias tan distintas, en un destino común compartido con los miles de refugiados españoles que llegaron a México a partir de 1939. Esa nueva experiencia vital les dará un marco de referencia común que en España no tenían y que contribuirá con esos recuerdos a crear una memoria colectiva del exilio español en México, en el cual las mujeres tuvieron un papel fundamental.

\section{Entrevistas consultadas}

Entrevista a Aurora Arnaiz, realizada por Pilar Domínguez, México, 1984.

Entrevista a María Gallegos realizada por Pilar Domínguez, México, 1984.

Entrevista a María Teresa, Madrid, 1992, Archivo de la Guerra Civil, Salamanca. Colección Mujeres en la Guerra Civil. SFO. 


\section{Referencias bibliográficas}

AGUILAR, Paloma. Memoria y olvido de la guerra civil española. Madrid: Alianza, 1996. . Políticas de la memoria y memorias de la politica. Madrid: Alianza, 2008.

ARNAIZ, Aurora. Retrato hablado de Luisa Julián. Madrid: Compañía Literaria, 1996.

LLONA, Miren. Memoria e identidades. Balance y perspectivas de un nuevo enfoque historiográfico. In: BORDERÍAS, Cristina. La bistoria de las mujeres perspectivas actuales. Barcelona: Icaria, 2007.

PASSERINI, Luisa. Torino operaia e fascismo. Roma: Laterza, 1985.

PLÁ, Dolores. El aroma del recuerdo. Narraciones de españoles republicanos refugiados en México. México: INAH, 2003.

RICOEUR, Paul. La memoria, la historia, el olvido. Madrid: Trotta, 2003.

VILANOVA, Mercedes. Rememoración en la Historia. Historia, Antropología y Fuentes Orales. Barcelona, n. 30, p. 23-40, 2003.

Resumo: A Guerra Civil Espanhola (1936-1939) tem uma posição privilegiada na historiografia da Espanha contemporânea. A recuperação das mulheres como sujeitos ativos na guerra (e no processo revolucionário que trouxeram ao lado republicano) é estudada por meio de várias fontes, tais como memórias escritas e testemunhos orais dos protagonistas. Este artigo, empregando os testemunhos orais de mulheres que viveram a Guerra Civil do lado republicano, busca avaliar o impacto do conflito nestas mulheres e em sua vida cotidiana. Estas entrevistas, obtidas segundo a abordagem da "história de vida", provêem a fundação para reconstruir as trajetórias e evolução pessoal destas mulheres enquanto, a mesmo tempo, permites a avaliação das distintas circunstâncias que circundavam cada sujeito.

Palavras-chave: Guerra Civil Espanhola; mulheres militantes; socialismo.

Memory and Forgetting among Spain's Republican Women

Abstract: The Spanish Civil War (1936-1939) holds a privileged position within the historiography of contemporary Spain. The recuperation of women as active subjects in the war (and the revolution process which they brought to the republican side) is also being studied from a variety of sources, among them written memories and oral testimonies of the protagonists. This paper, employing the oral accounts of two women that lived through the Spanish Civil War on the republican side, seeks to ascertain the conflict's impact on them and their everyday lives. These interviews, undertaken within a "life-story" approach, provide the foundation for reconstructing the trajectories and personal evolution of these women while, at the same time, allowing the evaluation of distinct circumstances that surrounded each subject.

Keywords: Spanish Civil War; militant women; socialism. 